\title{
Erratum to: Humic acid potentiometric response patterns: out-of-equilibrium properties and species distribution modeling
}

Vicente Rodrigues de Almeida ${ }^{1,2^{*}}$ and Bruno Szpoganicz ${ }^{1}$

\section{Erratum to: Chemical and Biological Technologies in Agriculture (2015) 2:17 \\ DOI 10.1186/s40538-015-0042-4}

After the publication of the original article [1], we noticed that Figs. 1-4 were ordered incorrectly and the figure captions did not correspond to the correct figures. The correct figure order and captions are provided below (Figs. 1, 2, 3, 4) and have also been updated in the original article. The publisher apologizes for any inconvenience caused.

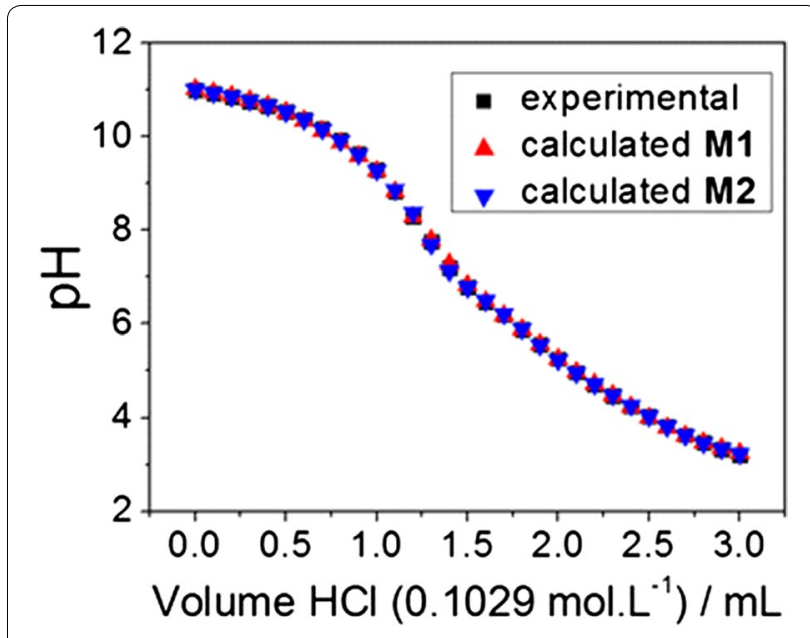

Fig. 1 Potentiometric titration curve for humic acids and the calculated results for models M1 and M2 (calculated models were obtained with resulting error function $\left.\sigma_{\text {fit }}<0.02\right)$

\footnotetext{
*Correspondence: vicentebra@hotmail.com

${ }^{2}$ Départment des Sciences de la Terre et de l'Environnement, Université Libre de Bruxelles, 50 Avenue F. D. Roosevelt, Brussels 1050, Belgium

Full list of author information is available at the end of the article
}
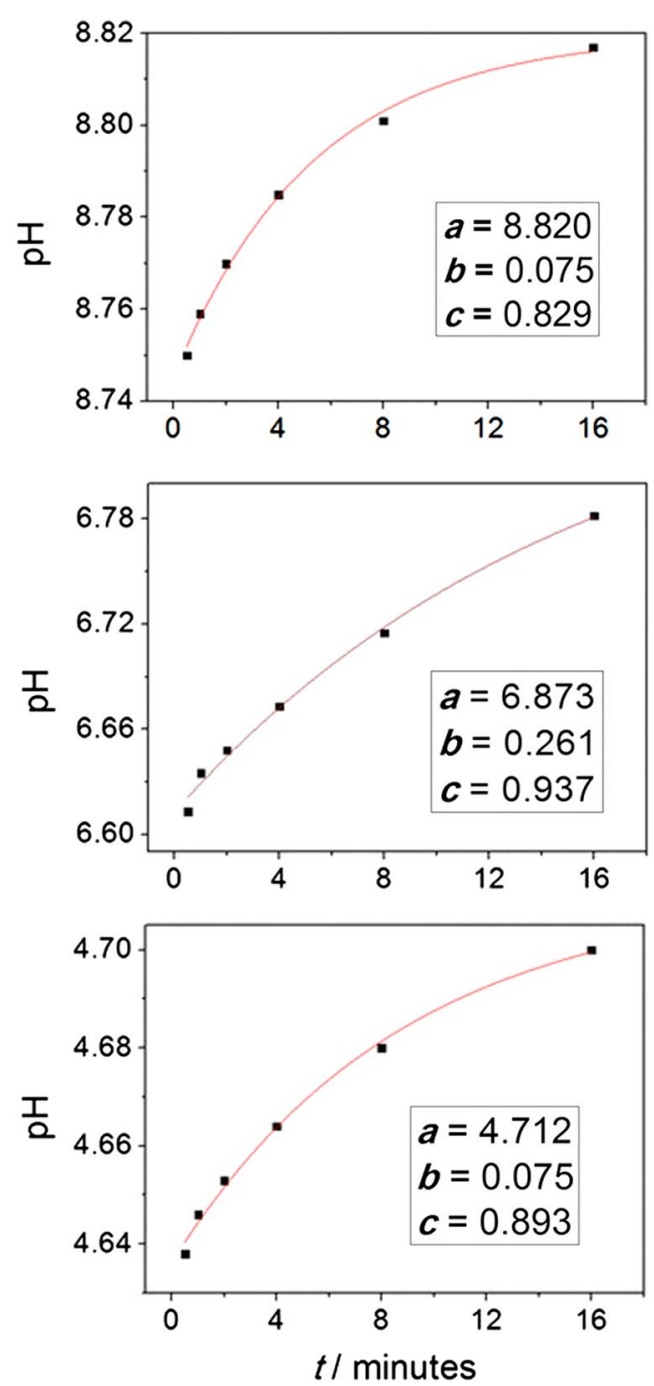

Fig. 2 pH stabilization curves for three selected titration points. The values for parameters $a$, b, and c (Eq. 5) of all titration points were used in the construction of Fig. 4 


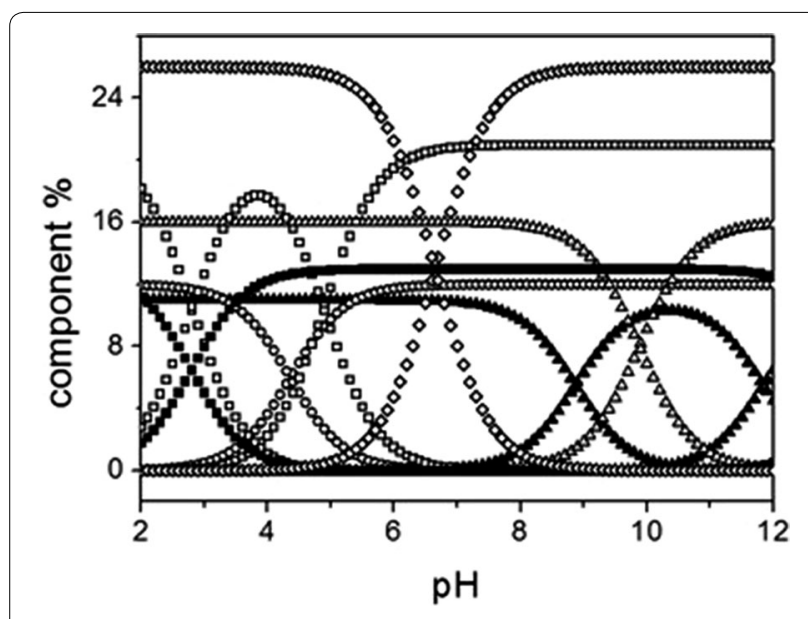

Fig. 3 Species distribution diagram obtained using model M2. The components are represented by the following symbols: open circle carboxylic, open square phthalic, open triangle phenolic, closed triangle catechol, closed square salicylic, and open diamond supramolecular
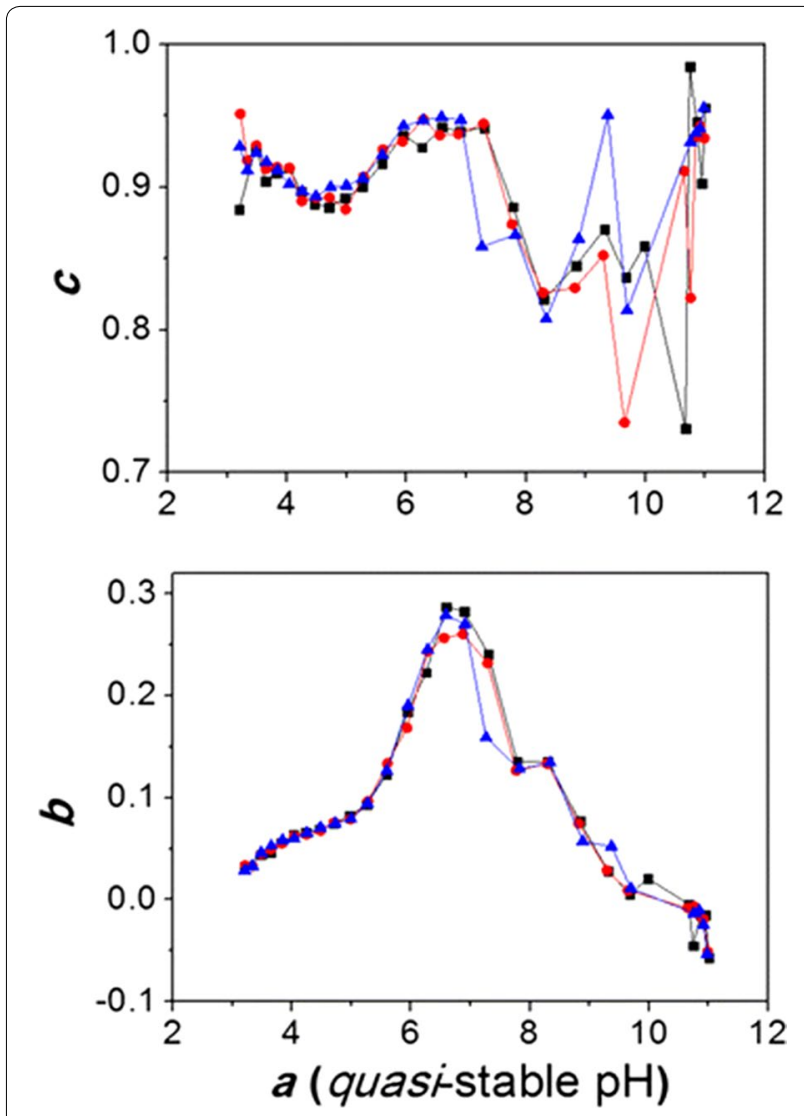

Fig. 4 Out-of-equilibrium potentiometric response patterns for parameters b (bottom) and c (top) as functions of a (see Eq. 5). Color lines represent the triplicate results

\section{Author details}

1 Departamento de Química, Universidade Federal de Santa Catarina, Campus

Universitário João Davi Ferrreira Lima, Florianópolis 88040900, SC, Brazil.

${ }^{2}$ Départment des Sciences de la Terre et de l'Environnement, Université Libre

de Bruxelles, 50 Avenue F. D. Roosevelt, Brussels 1050, Belgium.

The online version of the original article can be found under doi:10.1186/s40538-015-0042-4.

Received: 6 October 2015 Accepted: 6 October 2015

Published online: 17 December 2015

\section{References}

1. de Almeida VR, Szpoganicz B. Humic acid potentiometric response patterns: out-of-equilibrium properties and species distribution modeling. Chem Biol Technol Agric. 2015;2:17. 